\title{
HEAVY DUTY VEHICLES IMPACT RESEARCH ON TWO-LANE ROADS THROUGHPUT IN THE REPUBLIC OF SRPSKA
}

\author{
Marko Subotić ${ }^{1}$, Dunja Radović ${ }^{2}$ \\ 1,2 Faculty of Transport and Traffic Engineering, University of East Sarajevo, Doboj, Vojvode Mišića 52, \\ 74000 Doboj, Republic of Srpska, Bosnia and Herzegovina
}

Received 4 February 2019; accepted 27 April 2019

\begin{abstract}
In this paper, the HDV (Heavy Duty Vehicles) impact on throughput on two-lane roads in functional dependence on longitudinal slope has been analysed. The HDV impact in traffic flow has been shown by passenger car equivalent - PCE and based on the extensive empirical research in local conditions of the free flow, the adverse effect of this class of vehicles has been quantified. Data collection and analysis have been done in Bosnia and Herzegovina on main roads sections in the Republic of Srpska where PCE and HDV values have been measured on nine cross sections. By determining the time gap intervals, using data synthesis and analysis, PCE values relevant for the bus impact on two-lane roads throughput in local conditions have been reached. Resulting PCE values for all measured sections and for all variations of the longitudinal slope have been compared with (HCM, 2010). Based on the results of the research, mathematical model for determination of PCE for the HDV in function of longitudinal slope on two-lane roads has been developed. Model development has been based on the determination of the time gap according to the Greenshield's base model.
\end{abstract}

Keywords: PCE, two-lane road, free flow.

\section{Introduction}

The structure of traffic flow can be presented as an elementary indicator of all expected and unexpected changes in the parameters of traffic flow, which is classified as a homogeneous, non-homogeneous and conditionally homogeneous flow. Since the conditionally homogeneous flow in real conditions does not exist, it is necessary to introduce the concept of equivalent $\left(\mathrm{E}_{\mathrm{i}}\right)$ (PCE - passenger car equivalent) which is used to transform the nonhomogeneous traffic flow into homogeneous.

In the expert literature and engineering manuals (HCM, 2010; HBS, 2005;
HDM, 2003), different table values of the equivalents can be found, which are recommended for the transformation of heterogeneous traffic flow into a conditionally homogeneous traffic flow with various practical calculations. When analysing and calculating the practical capacity and the level of service, one of influential factors is the commercial vehicle factor (FHV), which contains the values of equivalents (PCE value) for different vehicle types and the percentage of the vehicles in a flow.

(Kockelman, 1998) points to the fact that the vehicle length has a negative impact on

${ }^{2}$ Corresponding author: dunja.radovic@sf.ues.rs.ba 
the traffic flow. In this study, different thirdorder polynomial models of traffic flow have been analysed in relation to flow density. The most significant influential factors of the road are related to a longitudinal slope, horizontal curve radius, roadway flatness, roadway lane width and visibility length.

Of all these factors, the greatest influence on PCE values has a longitudinal slope, so a considerable part of this research is devoted to it. (Rakha and Lucic, 2002) differentiate seven different conditions and types of roadways. In their research the value of PCE on good roadways is less variable.

\section{Literature Review}

Scientific papers based on the studies of PCE refer mainly to the estimation of PCE in relation to different vehicle categories under different traffic and road conditions (AlKaisy et al., 2002; Webster and Elefteriadou, 1999). (Elefteriadou et al., 1997) use average speed as a performance measure, while (Webster and Elefteriadou,1999) are identifying density as a performance measure for PCE determination. (Singh, 1999) uses the concentration of vehicles as a traffic characteristic to estimate the simulation model defined as a part of the road with the number of vehicles at a given time. However, (Khan and Maini, 1999) provide a broad overview of studies of the models of heterogeneous traffic flow throughput and, in the research, it has been concluded that the value of equivalents depends on the composition of the flow, saturation and location. (Chandra and Sikdar, 2000) propose a method for the PCE estimation for the heterogeneous traffic flow as a function of vehicle surface (length $\mathrm{x}$ width) and speed. (Al-Kaisy et al., 2002) use a factor of vehicle queue discharge as a performance measure for the PCE estimation during traffic flow congestion. (Bham and Benekohal, 2004) use the percentage of the section occupied by vehicles in order to present better traffic congestion conditions when a traffic flow is made up of the vehicles of heterogeneous length. (Sorensen, 1998) investigated the influence of commercial vehicles on Danish roads, on five road sections around Copenhagen, and the methodology used is based on the headway time interval (GAP).

It is evident that there are different approaches to the determination of PCE values in relation to different vehicle classes under different road and traffic conditions (Al-Kaisy et al., 2005). Additionally, PCE values are low at low throughput, and increase with increased throughput, where heavy vehicles have a significant impact on a small number of passenger cars (Giuffrè et al., 2015).

\section{Research Methodology}

The value of PCE is not a fixed but variable value and varies on a case-by-case basis. It is a variable value for different vehicle classes, and it is in functional dependence on several influential factors. Based on theoretical analysis, it can be made a hypothetical assumption that the PCE value for $\mathrm{HDV}$ in local conditions is in functional dependence on evident progress in the technology of development and manufacture of new vehicles. In addition, another hypothetical assumption is that the PCE value for HDV is primarily based on functional dependence on the structure of flow, driving and dynamic characteristics of vehicles and driver behaviour in local conditions and technical exploitation characteristics of the road. The definition of the concept for the studies of PCE calculation basically in 
general relies on the well-known and highlyused Greenshield's relation:

$$
P C E_{i}=\frac{H_{i}}{H_{P A}}
$$

$P C E_{i}$ - the passenger car equivalent of the $i^{\text {th }}$ vehicle category,

$H_{i}$ - the average value of headway interval of the $i^{\text {th }}$ vehicle category,

$H_{P A}$ - the average value of headway interval for a passenger car.

According to the (HCM, 2010) methodology, when defining the PCE value, all types of buses are covered by heavy vehicles. In addition, a longitudinal gradient implies an upgrade of $\geq 3 \%$ and longer than $600 \mathrm{~m}$, and two cases regarding the longitudinal slope are distinguished, when a two-lane road is two-way and when two-lane road is one-way (HCM, 2010). According to (HDM, 2003), there are two types of PCE factors in use: Passenger Car Equivalent (PCE) and Passenger Car Space Equivalent (PCSE) (Bennett and Greenwood, 2001).

\section{Research Results}

The aim of this research is to obtain PCE values for HDV (Heavy Duty Vehicles) through real models, observing individual vehicle classes in a function of longitudinal gradient. The dependence was obtained by empirical measurement of headway time intervals at the cross-section, at selected measurement locations of two-lane roads in a function of the extent of longitudinal gradient. The measurements were carried out on two-lane roads for two-way traffic, with the width of traffic lane of $3.0 \mathrm{~m}$. The situational plan elements of the two-way road are not a limiting factor, and in the measuring area there were no roadworks or any crossroads or joints. At the measurement locations, there is continuity in the extent of the longitudinal gradient with possible deviation of up to $\pm 0.5 \%$. Figure 1 shows the cross-section of measurement locations. The selection of locations with given longitudinal gradients were selected from the Data on Road Characteristics (P.E. Roads of the Republic of Srpska). The longitudinal slopes are selected intentionally and with sections greater than $1,000 \mathrm{~m}$.

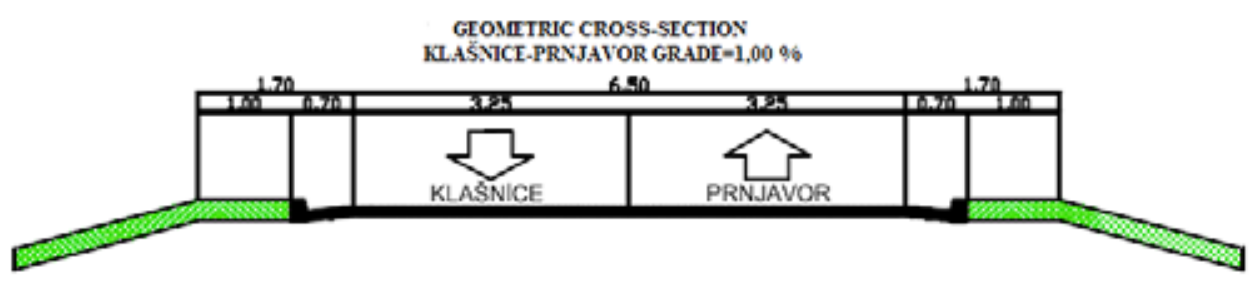

Fig. 1.

Cross-Section Klašnice - Prnjavor

Table 1 shows the recorded number of vehicles at individual measurement locations with the prominent class of HDV. 
Table 1

Recorded Number of HDV and Commercial Vehicles at Individual Measurement Locations and by Classes

\begin{tabular}{|c|c|c|c|c|c|}
\hline Measurement Location & $\begin{array}{c}\text { Category and } \\
\text { Number of Road }\end{array}$ & $\begin{array}{l}\text { Longitudinal } \\
\text { Gradient (\%) }\end{array}$ & HDV & ALL DV & $\begin{array}{c}\Sigma \text { All } \\
\text { Vehicles }\end{array}$ \\
\hline Rudanka-Doboj & M-17 & 0.00 & 66 & 175 & 1,009 \\
\hline Klašnice-Prnjavor & M-16.1 & 1.00 & 42 & 110 & 912 \\
\hline Klupe-Teslić & M-4 & 2.07 & 34 & 128 & 767 \\
\hline Klašnice-Prnjavor & M-16.1 & 3.20 & 56 & 131 & 908 \\
\hline Klašnice-Prnjavor & M-16.1 & 4.00 & 59 & 135 & 1003 \\
\hline Vrhovi-Šešlije & M-17.2 & 5.00 & 138 & 248 & 907 \\
\hline Obodnik-Klupe & M-4 & 6.03 & 38 & 137 & 736 \\
\hline Obodnik-Klupe & M-4 & 6.84 & 42 & 122 & 713 \\
\hline Obodnik-Klupe & M-4 & 7.45 & 35 & 130 & 811 \\
\hline Total & & & 510 & 1,316 & 7,766 \\
\hline
\end{tabular}

Further processing and data analysis was implemented in Microsoft Office Excel. For each measurement location, the PCE values of HDV, then the arithmetic mean (AM), standard deviation (STDEV) and variation coefficient were calculated based on recorded headway time intervals. The vehicles in the class of HDV were classified according to PCE values in the width class of 0.5 in order to obtain the distribution of PCE for the class of HDV. Thus, tabulated data were used for further analysis, determination of the regularity of distribution and estimation of the percentage values of $\mathrm{PCE}_{15 \%}, \mathrm{PCE}_{50 \%}$ and $\mathrm{PCE}_{85 \%}$. For this purpose, the Table Curve 2D v5.01 function analysis program was used (Figure 2). In this study, as the standard value of PCE for PC-PC headway (Passenger Car-Passenger Car), the value 1 was obtained.

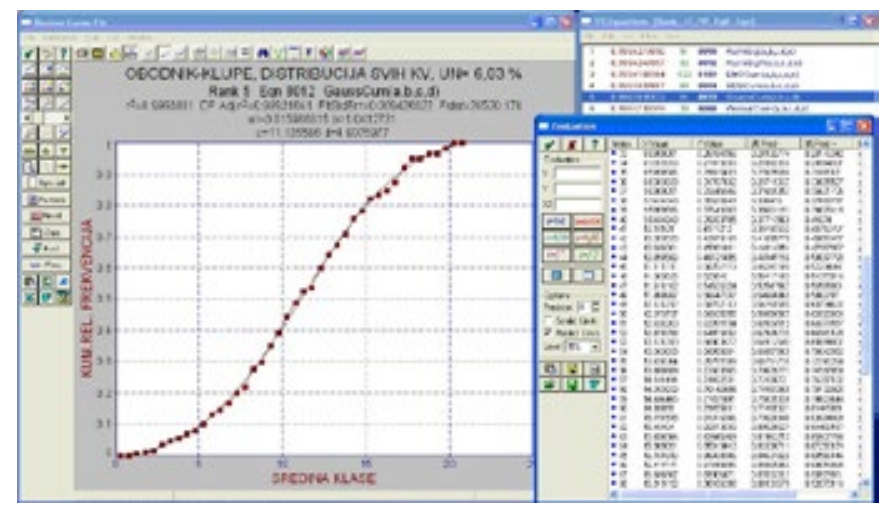

Fig. 2.

Determination of $P C E_{15 \%}, P C E_{50 \%}$ and $P C E_{85 \%}$ 
Figure 3 shows the obtained models of PCE for $\mathrm{HDV}$ in a function of upgrade. The diagrams also show the values of standard deviation depending on the longitudinal gradient. Models are required in the form of a second-degree polynomial:

$$
Y=A \cdot X^{2}+B \cdot X+C
$$

and the acceptable values of the correlation coefficient on the upgrade are obtained. The analysis of PCE on the slope resulted in a high correlation coefficient for HDV.
Additionally, based on the HCM tabulated values (HCM, 2000; HCM, 2010) and the results of the research, mathematical models, compared and analysed, were formed (Figures 4 and 5).

Based on the results obtained by analysing the functions of cumulative distribution in Table 3, the $\mathrm{PCE}_{15 \%}, \mathrm{PCE}_{50 \%}$ and $\mathrm{PCE}_{85 \%}$ dependence models for the two-lane roads in the Republic of Srpska were also obtained. The models show a high degree of correlative dependence $\left(R^{2}>0.5\right)$ given in Figure 6.

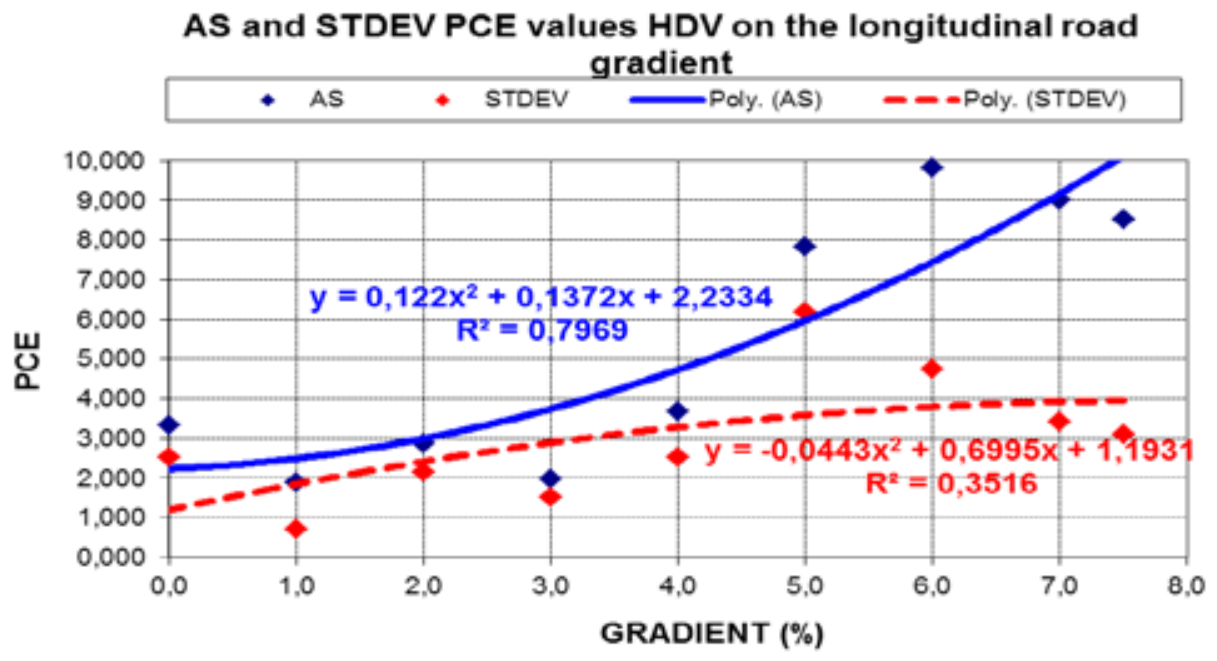

Fig. 3.

PCE Values for HDV in a Function of Longitudinal Gradient

In order to compare the research results obtained with the values obtained in HCM, it is necessary to determine their models for the whole range of slope in a form of one curve (for each version of HCM). $\mathrm{By}$ extracting the $\mathrm{PCE}$ values from each version of HCM (HCM, 1965; HCM, 1985; HCM, 1994; HCM, 2000; HCM, 2010), the representative values compared to field-derived models were obtained. In this way, values for HDV, given in Table 2, were obtained. 
Table 2

Empirically Obtained PCE and HCM Values at the Cross-Sections of Given Road Segments

\begin{tabular}{|c|c|c|c|c|c|c|c|c|c|}
\hline \multirow{2}{*}{$\begin{array}{l}\text { Measurement } \\
\text { Location }\end{array}$} & \multirow{2}{*}{$\begin{array}{c}\text { Category } \\
\text { and } \\
\text { Number } \\
\text { of Road }\end{array}$} & \multirow{2}{*}{$\begin{array}{l}\text { Longitudinal } \\
\text { Gradient (\%) }\end{array}$} & \multicolumn{2}{|c|}{$\begin{array}{c}\text { Heavy Duty } \\
\text { Vehicles }\end{array}$} & \multicolumn{5}{|c|}{ All Duty Vehicles } \\
\hline & & & AS & SD & $\begin{array}{c}\text { HCM- } \\
1965\end{array}$ & $\begin{array}{c}\text { HCM- } \\
1985\end{array}$ & $\begin{array}{c}\text { HCM- } \\
1994\end{array}$ & $\begin{array}{c}\text { HCM- } \\
2000\end{array}$ & $\begin{array}{c}\text { HCM- } \\
2010\end{array}$ \\
\hline Rudanka-Doboj & M-17 & 0.00 & 3.321 & 2.520 & 3.0 & 2.0 & 2.0 & 1.1 & 1.2 \\
\hline Klašnice-Prnjavor & M-16.1 & 1.00 & 1.893 & 0.710 & 3.0 & 2.0 & 2.0 & 1.1 & 1.5 \\
\hline Klupe-Teslić & M-4 & 2.07 & 2.865 & 2.160 & 3.0 & 2.0 & 2.0 & 1.1 & 1.5 \\
\hline Klašnice-Prnjavor & M-16.1 & 3.20 & 1.968 & 1.520 & 14.0 & 4.8 & 4.8 & 4.5 & 5.0 \\
\hline Klašnice-Prnjavor & M-16.1 & 4.00 & 3.685 & 2.520 & 22.0 & 6.3 & 6.3 & 6.4 & 7.6 \\
\hline Vrhovi-Šešlije & M-17.2 & 5.00 & 7.828 & 6.190 & 29.0 & 8.3 & 8.3 & 7.5 & 9.2 \\
\hline Obodnik-Klupe & M-4 & 6.03 & 9.817 & 4.750 & 39.0 & 11.0 & 11.0 & 9.1 & 10.3 \\
\hline Obodnik-Klupe & M-4 & 6.84 & 9.009 & 3.420 & 50.0 & 14.5 & 14.5 & 9.8 & 10.4 \\
\hline Obodnik-Klupe & M-4 & 7.45 & 8.527 & 3.090 & 5.909 & 3.390 & 56.0 & 14.5 & 14.5 \\
\hline
\end{tabular}

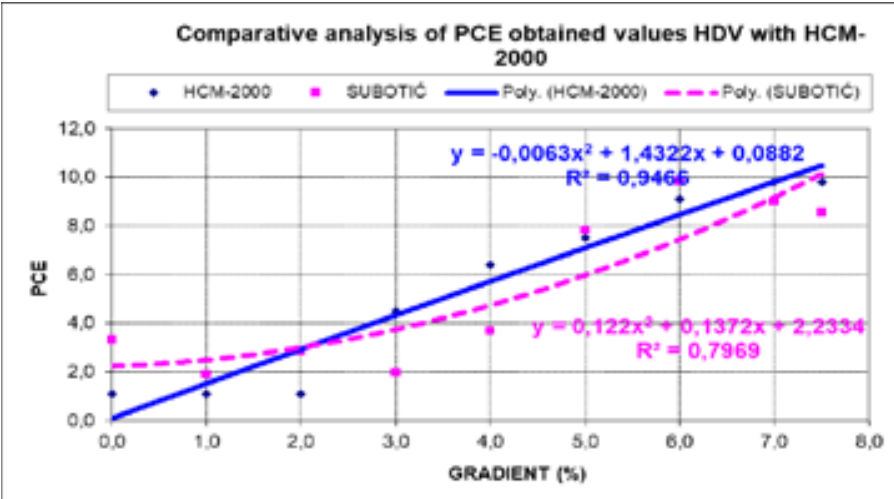

Fig. 4.

Comparative Analysis of Empirically Obtained Values with HCM-2000

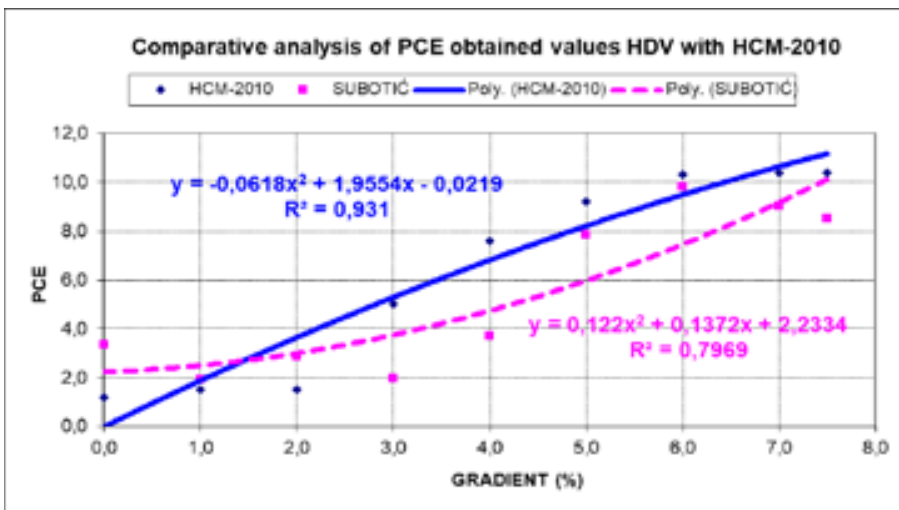

Fig. 5.

Comparative Analysis of Empirically Obtained Values with HCM-2010 


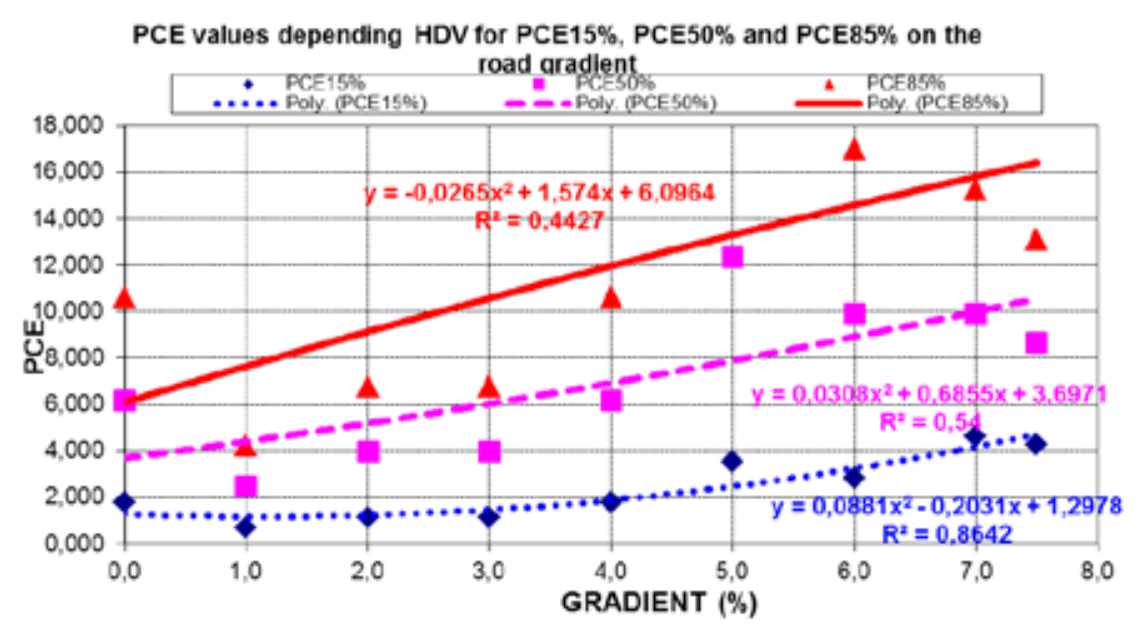

Fig. 6.

$P C E_{15 \%} P C E_{50 \%}$ and $P C E_{85 \%}$ for HDV on the Two-Lane Roads of RS in a Function of LG

Table 3

PCE Values for HDV (PCE ${ }_{15 \%} P C E_{50 \%}$ and $\left.P C E_{85 \%}\right)$ on Two-Lane Roads

\begin{tabular}{|c|c|c|c|c|c|}
\hline \multirow{2}{*}{$\begin{array}{c}\text { Measurement } \\
\text { Location }\end{array}$} & \multirow{2}{*}{$\begin{array}{c}\text { Category and } \\
\text { Number of Road }\end{array}$} & \multirow{2}{*}{$\begin{array}{c}\text { Longitudinal } \\
\text { Gradient (\%) }\end{array}$} & \multicolumn{3}{|c|}{ Heavy Duty Vehicles } \\
\cline { 4 - 6 } & M-17 & 0.00 & 1.273 & 4.455 & 7.636 \\
\hline Rudanka-Doboj & PCE 15\% & PCE 50\% & PCE 85\% \\
\hline Klašnice-Prnjavor & M-16.1 & 1.00 & 1.273 & 4.455 & 7.636 \\
\hline Klupe-Teslić & M-4 & 2.07 & 1.131 & 3.960 & 6.788 \\
\hline Klašnice-Prnjavor & M-16.1 & 3.20 & 1.131 & 3.960 & 6.788 \\
\hline Klašnice-Prnjavor & M-16.1 & 4.00 & 1.556 & 5.444 & 9.333 \\
\hline Vrhovi-Šrešlije & M-17.2 & 5.00 & 2.121 & 7.424 & 12.727 \\
\hline Obodnik-Klupe & M-4 & 6.03 & 2.121 & 7.424 & 12.727 \\
\hline Obodnik-Klupe & M-4 & 6.84 & 2.121 & 7.424 & 12.727 \\
\hline Obodnik-Klupe & M-4 & 7.45 & 2.121 & 7.424 & 12.727 \\
\hline
\end{tabular}

\section{Discussion and Conclusion}

The obtained results based on valid empirical research have confirmed the initial hypothesis of this paper, i.e. that the values of PCE for HDV in local conditions are in functional dependence on evident progress in the technology of development and manufacture of new vehicles. In the Republic of Srpska, in recent years, there has been a change in the structure of the fleet of vehicles in traffic flow, as well as the driving and dynamical characteristics of vehicles. This process is characterized by the fact that in addition to the greater sales of new vehicles of foreign manufacture, the accompanying process of the import of used vehicles has been represented and noticed. These prerequisites have, at first sight, resulted in paradoxically lower PCE values of all vehicle classes, and above all in $\mathrm{HDV}$ compared to the values recommended 
in the US manuals for road capacity.

The summarized results also indicate that the average value of equivalents for $\mathrm{HDV}$ on the horizontal position ( $\mathrm{LG}=0 \%$ ) is 3.321 (recommended 3). In addition, with an increase in longitudinal gradient, this value is progressively increasing, and, with $\mathrm{LG}=7.45 \%$, the PCE value for $\mathrm{HDV}$ is 8.527 (recommended 9). This proves that the increase in longitudinal gradient leads to the increase of the PCE value for HDV, and the PCE values are dispersed, which is particularly implied by the correlation coefficient $\mathrm{R}^{2}=0.7969$ for HDV. By this, the second additional hypothesis of this paper has also been confirmed, i.e. that the PCE values for HDV are in a function of dependence on the structure of flow, the driving and dynamic characteristics of freight vehicles and drivers in local conditions and the technical exploitation characteristics of the road. Particularly impressive is the PCE value for HDV at LG $=3.2 \%$, which is 1.968 , so the continual growth of PCE value is rapidly decreasing. This phenomenon explains the dispersion of PCE values for HDV in various road and ambient conditions that exist in traffic flow. The comparative analysis of the results obtained with the values of equivalents recommended in the US manuals for the road capacity (HCM, 2000; HCM, 2010) shows that the PCE values vary considerably and that for sizes larger than LG $=2 \%$, this research provides a lower PCE value for $\mathrm{HDV}$ than the current HCM manuals. With the increase in the longitudinal gradient, the PCE value for HDV increases from 3 to the value of 9, so that the curve is not linear, but with a lower correlation coefficient compared to the HCM recommendations $\left(\mathrm{R}^{2}>0.93\right)$, indicating a significant fluctuation of the PCE values. Taking into account that only the values of PCE on two-lane roadways for HDV were analysed in the paper, in subsequent research tasks it is necessary to pay particular attention to the analysis of PCE at the downgrade. This would provide recommendations on the obtained PCE values for the local conditions applicable in engineering practice.

\section{References}

Al-Kaisy, A.F.; Hall, F.L.; Reisman, E.S. 2002. Developing passenger car equivalents for heavy vehicles on freeways during queue discharge flow, Transportation Research Part A: Policy and Practice 36(8): 725-742.

Al-Kaisy, A.; Jung, Y.; Rakha, H. 2005. Developing passenger car equivalency factors for heavy vehicles during congestion, Journal of transportation engineering 131(7): 514-523.

Bham, G.H.; Benekohal, R.F. 2004. A high fidelity traffic simulation model based on cellular automata and car-following concepts, Transportation Research Part C: Emerging Technologies 12(1): 1-32.

Bennett, C.R.; Greenwood, I.D. 2001. Modelling road user and environmental effects in HDM-4. World Road Association (PIARC), Paris/The World Bank, Washington, DC.

Chandra, S.; Sikdar, P.K. 2000. Factors affecting PCU in mixed traffic situations on urban roads, Road and transport research 9(3): 40-50.

Elefteriadou, L.; Torbic, D.; Webster, N. 1997. Development of passenger car equivalents for freeways, two-lane highways, and arterials, Transportation Research Record: Journal of the Transportation Research Board 1572(1): 51-58.

Giuffrè, O.; Granà, A.; Mauro, R.; Silva, A.B.; Chiappone, S. 2015. Developing passenger car equivalents for freeways by microsimulation, Transportation Research Procedia 10: 93-102. 
HBS. 2005. Handbuch für die Bemessung von Straßenverkehrsanlagen [In English: Manual for dimensioning road traffic facilities]. Forschungsgesellschaft für Straßenund Verkehrswesen. FGSV-Verlag.

HCM. 1965. Highway Capacity Manual. Special report 87, Highway Research Board, Publication 1328, Washington D.C. USA.

HCM. 1985. Highway Capacity Manual. Special report 209, Transportation Research Board, National Research Council, Washington, DC., USA.

HCM. 1994. Highway Capacity Manual. Special report, Third Edition, Transportation Research Board, National Research Council, Washington, DC., USA.

HCM. 2000. Highway Capacity Manual. Transportation Research Board, National Research Council, Washington, DC., USA.

HCM. 2010. Highway Capacity Manual. Transportation Research Board, National Research Council, Washington, DC.

HDM. 2003. International Study of Highway Development and Management (ISOHDM) HDM-4 Series. Version 3.0. December, 2003.
Khan, S.I.; Maini, P. 1999. Modeling heterogeneous traffic flow, Transportation research record 1678(1): 234241.

Kockelman, K.M. 1998. Changes in flow-density relationship due to environmental, vehicle, and driver characteristics, Transportation Research Record: Journal of the Transportation Research Board 1644(1): 47-56.

Rakha, H.; Lucic, I. 2002. Variable power vehicle dynamics model for estimating truck accelerations, Journal of transportation engineering 128(5): 412-419.

Singh, B. 1999. Simulation and animation of heterogeneous traffic on urban roads. [Ph. D Thesis]. Indian Institute of Technology Kanpur, Kanpur, India.

Sorensen, H. 1998. Determining passenger car equivalents for freeways. In Third International Symposium on Highway Capacity Transportation Research Board Highway Capacity and Quality of Service Committee, Danish Road Directorate (No. Volume 2).

Webster, N.; Elefteriadou, L. 1999. A simulation study of truck passenger car equivalents (PCE) on basic freeway sections, Transportation Research Part B: Methodological 33(5): 323-336.

\section{jitte 162}

